\title{
Read This, Please? The Role of Politeness in Customer Service Engagement on Social Media
}

\author{
Yuheng Hu, Ali Tafti, David Gal \\ University of Illinois at Chicago \\ Contact: yuhenghu@uic.edu
}

\begin{abstract}
People are increasingly turning to social media for help. According to a recent report by Twitter, over 5.5M customer service-related tweets are generated per month. In this work, we aim to explore firms' strategy when engaging customers regarding their concerns and complaints on Twitter. Specifically, we focus on how politeness, a linguistic factor indicating how a customer is questioning or complaining rather than the content of a query, affects firms' customer service engagement strategy. We develop a novel text mining methodology to mine politeness from tweets. Using this approach, our estimation results show several interesting results, including that firms are more likely to respond to more polite customers, and that this effect is augmented for customers with high social status. However, firms are more likely to engage impolite customers with a high social status in a private channel such as through direct messaging.
\end{abstract}

\section{Introduction}

People are increasingly turning to online resources for help. Such needs often cannot be resolved merely through information posted on a website and require customized help from real people. A manifestation is the phenomenon of individuals contacting firms directly on social media platforms like Twitter with the expectation of a helpful and human response for answers to their specific questions and complaints. According to a recent McKinsey's analysis, $30 \%$ of social media users prefer customer care on social media. ${ }^{1}$

Compared to traditional private channels for customer service such as the toll-free (1-800) number, social media platforms present new challenges and

\footnotetext{
${ }^{1}$ https://hbr.org/2012/12/turn-customer-care-intosocial
}

opportunities for customers and firms. On the one hand, Twitter and Facebook have a transparent and open format where the public can view messages and conversations between individuals. Therefore, firms are motivated to build and improve their brand image by engaging and satisfying customers publically on social media. Such public engagement can clear up any complaints or diffuse potential negative sentiment that could otherwise fester on the social media platform, in turn, promoting a positive attitude towards the firm's brand. On the other hand, engaging every customer is costly and nearly impossible, especially when a firm receives or gets mentioned by a massive number of social media posts in a short period of time. More importantly, engaging customers publicly also bears risks, because some customer complaints may not be ultimately resolved, and some people are prone to becoming even more inflamed or negative in response to the firm's attempt to engage with them. Given this dilemma, for firms, an effective social media strategy for dealing with customer queries is essential for successfully managing customer perceptions of the firm (a notion also advocated in Twitter's playbook ${ }^{2}$ ). For example, it may sometimes be better for firms to direct incessantly negative customers towards private channels of communication such as telephone, email, or direct messaging features of the platform, or to avoid engaging those customers in a public forum altogether, particularly if the firm can anticipate that the customer's sentiment is likely to remain negative. Such a strategy corresponds to a fundamental precept of the modern social media age: don't feed the trolls; ${ }^{3}$ in other words, don't inflame or encourage negative commentators by engaging them publicly.

Despite the rapid growth of customer service on social media, research in this area is still in its infancy thus far. In this study, we aim to explore firms' strategy when engaging customers regarding their

\footnotetext{
${ }^{2} \mathrm{https}$ ://twitter.app.box.com/v/customer-service-ontwitter

${ }^{3}$ https://en.wikipedia.org/wiki/Internet_troll
} 
concerns and complaints on Twitter. Past research in the service literature has shown that the success of a request on forums, Q\&A sites, and crowdfunding campaigns depends not only on what the request is about, but, crucially, on how the request is being asked and who is doing the asking $[30,31,1]$. Building on this research, here we focus on how a fundamental feature of communication, namely the tone of communication, and more specifically, the politeness of the communication, affects firms' customer service engagement strategy. Tone is a linguistic factor indicating how a customer is complaining rather than the content of the query, with politeness being the most common element of tone attached to communication $[25,7]$.

Our key hypothesis is that firms' likelihood of public response to a customer question or complaint on Twitter increases with the politeness of the customer's message. We argue that politeness is likely to reflect the attitude of the customer towards the firm as well as the customer's predisposition to being satisfied with the firm's response and, in turn, the customer's predisposition to express positive or negative sentiment subsequent to the firm's response. Therefore, politeness is a significant factor in firms' decision to respond to customer complaints on Twitter, to the extent that firms aim to amplify the broadcast of positive sentiment about them, and to attenuate the broadcast of negative sentiment towards them. To examine our hypothesis, we first collected data from Twitter using the public API from September $1^{\text {st }} 2016$ to December $1^{\text {st }}$ 2016. We monitored tweets sent to (i.e., mentioning) 220 customer service-related Twitter accounts of firms and reconstructed the Twitter conversation threads between customers and firms using the meta data of these tweets about concerns and complaints. As expected, not all tweets sent to firms receive a response; the average response rate is $44.8 \%$. The time it takes to receive a response also varies by linguistic features of the tweets and social status of the customers, and it differs by firms, supporting the idea that firms have social media strategies for engaging with customer complaints. We next develop a novel text mining approach to mine politeness from tweets and use the number of an individual's followers on Twitter to operationalize social status.

Our estimation results show several interesting results. First, firms are more likely to respond to more polite customers even when they are complaining, indicating that firms tend to engage those who appear more reasonable and pleasant, and who behave prosocially towards their addressee. Second, firms are more likely to respond to tweets sent by customers with a higher number of followers, suggesting that firms do take consumer's social status on Twitter into account in determining whether or not to respond. Third, when considering the interaction between politeness and social status of the customer, we find, counterintuitively (albeit consistent with our theorizing), that the more followers individuals have, the less likely firms are to engage them publically when their tweets are impolite. Conversely, firms are more likely to direct impolite customer with a high social status to a private channel such as to direct messaging. These findings are consistent with the idea that firms recognize the higher risk associated with antagonizing impolite opinion leaders through failing to respond to their queries, but that firms also identify risk in publically engaging impolite opinion leaders (i.e., doing so can exacerbate the broadcasting of negative sentiment towards the firm). Supporting this view, we find that when firms engage impolite customers publically the sentiment of their tweets actually becomes even more negative. This is in contrast to polite customers where engagement leads to improved sentiment. Therefore, using a private channel to avoid engaging impolite customers (i.e. feeding the trolls) can be considered a risk-averse strategy for firms.

This work makes several contributions to the literature: First, we develop novel data mining approaches to examine the effect of social and linguistic factors on customer service interactions on Twitter. Second, our results provide evidence for the nature of firms' strategic engagement with customers on the publically broadcast platform Twitter. Our findings extend recent work, such as that by [27], that focus on the correlation between customer-firm relationships and firm intervention in customer service, by enabling a richer perspective. To the best of our knowledge, we are among the first to analyze customer and firm-level dynamics and to evaluate the effects of social and linguistic aspects of customer service engagement on social media. Understanding the dynamics and factors of successful customer service engagement has the potential to substantially improve customer-firm relationships, the customer experience, and brand image management, among other outcomes. In addition to these practical benefits, understanding the factors that influence customer-service interactions has implications for research in online communications, social psychology, information systems, marketing, and related areas.

\section{Background}

\subsection{Customer Service and Customer Rela- tionship Management}


Sen and Sinha define Customer Relationship Management (CRM) as the overall process of building and maintaining profitable customer relationships by delivering superior customer value and satisfaction [36]. With social media, customers are no longer limited to a passive role in their relationship with a company. Instead, they can easily spread word of mouth (WOM) about a firm or a brand to large audiences on social media. It also enables firms to listen to and engage with their customers directly, potentially fostering a positive attitude towards a brand [32].

A common task in CRM is to provide customer service. Regardless of how excellent the service a company delivers, every company often makes mistakes in meeting the expectations of customers [32]. Complaint management refers to the strategies used by the brands to resolve customer's complaints regarding firm's mistakes and to improve ineffective products or services in order to establish a firm's reliability in the eyes of the customers, or neglect the risk of negative WOM [34, 40]. Previous studies indicate that failures and mistakes do not necessarily lead to customer dissatisfaction, since most customers accept that things may sometimes go wrong [12]. Instead, the service provider's response to the failure or lack of response is the most likely cause of dissatisfaction [37]. Past research also examined how organizational responses to complaints future consumer behavior [11,39].

\subsection{Customer Service using Social Media}

Although social media has gained tremendous attention from researchers over recent years, research in the context of social media-based CRM is still in its infancy. Sreenivasan et. al. analyzed tweets that mention three specific airlines and identified various categories of user posts such as tweets for sharing general information, asking questions and providing personal updates [38]. According to the analysis, the airlines being studied did not appear to be as responsive to users' postings as expected. Gunarathne et al. analyzed tweets exchanged between customers and three major airlines in North America and found that these airlines pay significantly more attention to customer with more followers [16]. Most recently, the same authors results showed that complaining customers with a higher number of followers are more likely to be satisfied after engaging with firms [17]. $\mathrm{Ma}$ et al. found that although customer service intervention improves customer relationships, it also encourages more complaints later. As a result, firms are likely to underestimate the returns on service intervention [27].

Our research contributes to the growing body of research on social media-based customer service. Unlike past work which mainly focused on the effect of complainant profile in firm's service intervention (e.g., $[16,17])$ or the consequence of firm's service intervention (e.g., [27]), we develop novel approaches to explore the content of complains and understand how the tone of the complainant affects firm's service intervention.

\section{Hypotheses Development}

\subsection{Politeness}

The tone of communications is an important factor in how messages are received and interpreted and in how they advance relationship building, problem solving, and task accomplishment [19]. One theoretical lens to explain this kind of behavior is politeness theory, which describes how people phrase communications in a way that takes into consideration the feelings of others [7]). Politeness has been found to be intimately related to the dynamics of social interactions and is often a decisive factor in whether those interactions go well or poorly $[33,3]$.

In the context of complaining behaviors, justice theory has been successfully applied in a variety of settings and is the prevalent model $[15,40]$. It has three components. Distributive justice models the equity perceived by the consumer in the complaint handling process [28]. Procedural justice studies how rules and procedures impact the overall perception of justice [40]. Interactional justice analyses the relationship between the complaining customer and the personnel in charge of the complaint handling. [26] found that the antecedents of interactional justice are related to the respect of people, and politeness and empathy are important dimensions of respect $[29,4]$. Moreover, Kaplan observed that "people desire to be paid respect", and honorifics and other politeness markers such as words like "please" and "could you" can be "the coin of that payment" [23]

Given, from the above, that politeness tends to reflect the regard with which a complainant holds the addressee, it is reasonable to surmise that more polite complaints are likely to convey a higher regard towards the firm (even if the customer is experiencing a problem with a product or service); conversely, impolite tweets are likely to convey a relatively low regard for the firm. Thus, as a first order effect, responding selectively to more polite complaints is likely to broadcast more positive net sentiment towards the firm. This leads us to the following: 
Hypothesis 1: A firm is more likely to respond to a more polite tweet sent to it by a customer.

\subsection{Politeness and Social Status}

Politeness marking is one aspect of the broader issue of how language relates to power and social influence, which has been studied in different contexts $[19,35]$. Burke and Kraut study the question of how and why specific individuals rise to administrative positions on Wikipedia [8], and [10] show that power differences on Wikipedia are strongly correlated with politeness.

On Twitter, users interact by following people who post interesting tweets and the number of followers of a user directly represents the size of the audience that particular user has. The recent work by [9] on users' social influence on Twitter indicates that popular users who have high in-degree (number of followers) are not necessarily influential in terms of spawning retweets or mentions but can hold significant influence over a variety of topics. Therefore, in order to prevent a customer with a large number of followers from spreading negative WOM (e.g., starting from a complaining tweet) about service failure or bad experience with a firm or a brand, firms would have a stronger incentive to respond to such customers. Therefore, we have the following control hypothesis:

Hypothesis 2: Following a complaint, the social status of the complaining customer will be positively associated with the likelihood of being responded to by the firm.

However, engaging customers publicly also bears risks, because some customer complaints might not ultimately be resolved, and some people are prone to become even more inflamed or negative publically in response to the firm's attempt to engage with them. The situation would be worse for the firm's image if the customer has a high social status. In such cases, following a utilitarian perspective [27], we have:

Hypothesis 3: There will be a positive interaction between politeness and social status on the likelihood of firm response. In other words, politeness will have a more positive impact on the likelihood of firm response for high social status customers than for low social status customers.

At first blush, Hypothesis 3 appears counterintuitive. Specifically, we expect firms to attend more diligently to high status customers, and therefore we might also expect firms to be particularly likely to respond to such customers when they are being impolite so as to dampen their negative sentiment towards the firm and prevent this sentiment from reaching the customer's followers. However, we have theorized that impolite customers will be predisposed to react negatively to firm engagement. This leads us to the following additional hypotheses:

Hypothesis 4a: There will be a negative interaction between politeness and social status on the likelihood of being directed by the firm towards a private channel such as direct message. In other words, impoliteness will increase the likelihood of being directed to a private channel more for high social status customers than for low social status customers.

Hypothesis 4b: When the firm engages a customer in response to a complaint, politeness will be positively correlated with sentiment change. Stated differently, impoliteness of the complaining tweet will be associated with a more negative change in sentiment following firm engagement.

\section{Measuring Politeness of Tweets}

The seminal work by Brown and Levinson is among the first to systematically study politeness theory [7]. Brown and Levinson noted that people regularly depart from strictly efficient conversation by using behaviors designed to mitigate or soften direct expressions of desire, intent, request or command. For example, when a person speaks to another person "Please help me." The use of "please" is unnecessary for a truthful, relevant or clear expression of the speaker's wish and is not required to express his or her overt intent. The use of such violations are called linguistic politeness strategies by Brown and Levinson and they have two main forms: positive strategies and negative strategies. In particular, positive politeness strategies such as use of vocatives, inclusive pronouns, and expressions of agreement, understanding, cooperation and sympathy demonstrate intimacy, proximity, a friendly attitude and a claim of common ground between the speaker and the addressee. Conversely, negative politeness strategies such as hedges, indirect inquiries, subjunctives, and apologies demonstrate the speaker's wish not to be seen as imposing on the addressee.

Both positive and negative politeness strategies are frequently used and are highly effective in daily communications [33, 34, 35, 6]. Drawing on this work, we built our machine learning-based politeness model using the politeness strategies identified by 
[7]. Table 1lists the details of the politeness strategies used by our model.

\begin{tabular}{|l|l|l|}
\hline & Strategy & Example \\
\hline 1 & Gratitude & $\begin{array}{l}\text { Thanks in advance!/I really appre- } \\
\text { ciate your help! }\end{array}$ \\
\hline 2 & Deference & You did an amazing job... \\
\hline 3 & Greeting & $\begin{array}{l}\text { Hi @ attacares.../Hey, I just tried } \\
\text { to... }\end{array}$ \\
\hline 4 & Group identity & $\begin{array}{l}\text { Help me please, guys.../Help me } \\
\text { with this bag here, will you pal? }\end{array}$ \\
\hline 5 & Presuppose & $\begin{array}{l}\text { Ok, let's stop that problem.../We } \\
\text { should do this... }\end{array}$ \\
\hline 6 & Please & $\begin{array}{l}\text { Please help.../Could you please } \\
\text { explain?... }\end{array}$ \\
\hline 7 & 1 st person & $\begin{array}{l}\text { I have a problem with.../I cannot do } \\
\text { it... }\end{array}$ \\
\hline 8 & Apologizing & Sorry to bother you... \\
\hline 9 & Indirect & By the way, I also want to... \\
\hline 10 & $\begin{array}{l}\text { Direct ques- } \\
\text { tion/start }\end{array}$ & $\begin{array}{l}\text { Why does this happen?/So can you } \\
\text { solve it or not? }\end{array}$ \\
\hline 11 & 2nd person & $\begin{array}{l}\text { You come here.../You should not do } \\
\text { this to me... }\end{array}$ \\
\hline 12 & Hedges & $\begin{array}{l}\text { I assume this is reason.../I'm not an } \\
\text { expert but }\end{array}$ \\
\hline 13 & $\begin{array}{l}\text { Disagreement } \\
\text { avoidance }\end{array}$ & I sort of think.../I kind of want... \\
\hline 14 & Pessimistic & $\begin{array}{l}\text { Could/Can/Would/Will you help } \\
\text { me? }\end{array}$ \\
\hline 15 & Positive lexicon & Awesome!/This is great ... \\
\hline 16 & Negative lexicon & $\begin{array}{l}\text { I dislike your design.../Really bad } \\
\text { service... }\end{array}$ \\
\hline
\end{tabular}

Table 1 Politeness Strategies. Gratitude and deference (lines 1-2) are ways for the speaker to balance out the social cost of the request, question, or complaint on the addressee. Greetings (line 3 ) are another way to build a positive relationship with the addressee. Group identity (line 4) and presupposition (line 5) are also tools for positive politeness by claiming common ground between speaker and addressee. The remaining cues in Table 1 are negative politeness strategies, serving the purpose of minimizing the imposition on the addressee. Apologizing (line 8) deflects the social threat of the request/question/complaint by attuning to the imposition itself. Indirect (line 9) is another way to minimize social threat. Conversely, being direct or using second-person forms such as "you" as a form of direct address is less polite (lines 10-11). Hedges (line 12) provide the addressee with a face-saving way to deny the request. Similarly, disagreement avoidance (line 13) indicates the speaker is vague about the opinions so as not to disagree explicitly. By being pessimistic (line 14) the speaker signals the absence of an intention to coerce the addressee. Finally, we also include terms from the sentiment lexicon (Liu et al., 2005). The positive terms are useful markers for positive politeness emphasizing a positive relationship with the addressee (line 4), while the avoidance of negative sentiment can potentially minimize the imposition as well. It is worth noting that many of these features are correlated with each other, but this is reasonable as Brown and Levinson point out that politeness markers are often combined to create a cumulative effect of politeness (Brown and Levinson, 1978).

\subsection{Predicting politeness}

We build and compare two supervised classifiers with two different feature sets for automatically classifying tweets according to politeness - an SVM classifier with unigram feature (SVM-BOW), an SVM classifier with linguistic features based on politeness strategies in addition to unigram (SVMLing); a logistic regression model with classifier with unigram feature (LR-BOW); a logistic regression model with linguistic features based on politeness strategies in addition unigram feature (LR-Ling). To build linguistic features, for each customer's tweet, we first apply Tweeboparser, a Twitter-specific NLP tool to generate dependency parse. Next, we extract politeness strategy markers in Table 1 using regular expression matching on the parse in addition to specialized lexicons. For example, for the hedges (Table 1 , line 12), we check if a post contains a nominal subject (e.g., noun or noun phrase) dependency edge pointing out from a hedge verb from the hedge term list created by [22]. As a result, we build a list of binary features for each Twitter post, indicating whether the post exhibits the corresponding politeness strategy markers.

Next, to get the training and testing data to train our models, we label a large portion of over 5,000 tweets using Amazon Mechanical Turk (AMT). For each tweet, the annotator had to indicate how polite she perceived it to be by using a slider with values ranging from "very impolite" to "very polite". Each request was labeled by three different annotators. We selected annotators by restricting their residence to be in the U.S. and by conducting a linguistic background questionnaire. Since politeness is highly subjective and annotators may have inconsistent scales, we applied the standard $z$-score normalization to each worker's scores. Finally, we define the politeness score of a tweet by averaging the scores from the annotators.

\begin{tabular}{|c|c|c|}
\hline & Unigram & $\begin{array}{c}\text { Linguistic + Uni- } \\
\text { gram }\end{array}$ \\
\hline SVM & $71.12 \%$ & $77.44 \%$ \\
\hline $\begin{array}{c}\text { Logistic Re- } \\
\text { gression (LR) }\end{array}$ & $74.51 \%$ & $81.54 \%$ \\
\hline
\end{tabular}

Table 2 Classification Performance 
We train and evaluate the classifiers with a standard leave-one-out cross validation procedure. From the testing results in Table 2, the linguistically informed features give $3-4 \%$ average improvement over the unigram features. This confirms that our politeness theory-inspired features are indeed effective in practice. Moreover, we find logistic regression performs better than SVM. Therefore, in the next section we apply the trained LR-Ling model to automatically annotate a much larger set of Twitter conversation (about 800,000 ) with politeness labels, enabling us to relate customer politeness to firm behaviors.

\section{Econometric Model}

\subsection{Data Collection}

We used Twitter public API to collect over $1.5 \mathrm{M}$ tweets mentioning the official account or customer service-specific account of 220 firms from September 1* 2016, until December 1*2016. Note that some firms may have multiple Twitter accounts, e.g., AT\&T has a main account (@att) for sharing company news whereas @attcares is for any customer service related questions. In this case, we only monitored the customer service accounts. Based on that, we reconstructed $400 \mathrm{~K}$ Twitter conversation threads between customer and firm based on the metadata of their tweets. If a user tweet is matched with one or more replies from the firm, it is considered responded. On average, only $44.6 \%$ of tweets received a response. For those responded tweets, $99.5 \%$ out of the responded user tweets had received the response within 7 days. Hence, we consider a user tweet as having received a response if the firm replied to the particular user tweet within 7 days after the user tweet is posted. Finally, since our focus is on firms' customer engagement strategy with respect to complaints and service request, we developed a logistic regression with standard linguistic features (e.g., ngrams, TF-IDF, punctuations), to process all the threads to determine whether it was a complaint or a compliment.

\subsection{Variable Definition}

$\mathrm{H} 1-\mathrm{H} 3$ requires us to examine one dependent variable. It is: 1) whether a firm responds to a customer complaint or not. $\mathrm{H} 4$ requires us to examine two more dependent variables: 2) whether a firm directs a customer towards a private channel such as a direct message channel, and 3) the degree of the sentiment change between the customer's first and last tweet of a thread. For independent variables, we measure both customer-level and firm-level variables. We report our measures and descriptive statistics in Table 3.

We define variables as follows:

- Response: Whether a firm responds to a customer tweet about complaint or concern or not

- DM: Whether a firm directs a customer towards a private channel such as a direct message channel. We measure it by tracking the keywords "DM", "Direct message" in firm's tweets in responding to the customer's complaint or concern

- SentimentChange: The degree of the sentiment changes between the customer's first and last tweet of the thread. We measure the tweet sentiment between -1 to 1 using Vader, a rule based sentiment analysis tool designed for tweets (Hutto and Gilbert 2014)

- \#Following: The total number of people a customer is following on Twitter. We apply $\log$ transformation due to data skewness

- \#Follower: The total number of people who are following the customer on Twitter. We apply log transformation due to data skewness

- \#Tweets: The total number of tweets the customer has posted on Twitter. We apply log transformation due to data skewness

- \#Likes: The total number of likes the customer has on Twitter. We apply log transformation due to data skewness

- isVerified: Whether the customer has a verified Twitter account or not

- AvgTweetLength: The average length of customer's tweet about complaint or concern sent before getting responded by the firm

- \#hashtags: The average number of hashtags in customer's tweet about complaint or concern sent before getting responded by the firm

- \#mentions: The average number of mentions (by counting "@") in customer's tweet about complaint or concern sent before getting responded by the firm

- Evidentiality: Whether a URL is in the customer's tweet about complaint or concern detected by a regular expression

- Politeness: Politeness of the customer's tweet about complaint or concern. We compute politeness from tweet text content using the approach described in section 4 . 
- HourOfDay: Hour of the customer's tweet about complaint or concern from 1 to 24

- DayofWeek: Day of the customer's tweet about complaint or concern from 1 to 7

- BrandFollower: The total number of people who are following the firm on Twitter. We apply log transformation due to data skewness

- BrandFollowing: The total number of people the firm is following on Twitter. We apply log transformation due to data skewness

- BrandTweets: The total number of tweets the firm has posted on Twitter. We apply log transformation due to data skewness

\begin{tabular}{|l|l|l|}
\hline Variable & Mean & Std \\
\hline Response & 0.44 & 0.49 \\
\hline DM & 0.27 & 0.41 \\
\hline SentimentChange & 0.11 & 0.12 \\
\hline \#Following & 764.5 & $8,437.5$ \\
\hline \#Follower & 182.2 & 5,2336 \\
\hline \#Tweets & 1,898 & 1,025 \\
\hline \#Likes & 458 & 412 \\
\hline isVerified & 0.01 & 0.14 \\
\hline AvgTweetLength & 18.0 & 19.5 \\
\hline \#hashtags & 0.25 & 0.75 \\
\hline \#mentions & 1.4 & 1.2 \\
\hline Evidentiality & 0.21 & 0.50 \\
\hline Politeness & 0.54 & 0.11 \\
\hline HourOfDay & 10.0 & 7.3 \\
\hline DayofWeek & 2.9 & 2.7 \\
\hline BrandFollower & 196,587 & 105,250 \\
\hline BrandFollowing & 6,023 & 6,425 \\
\hline BrandTweets & 392,988 & 256,547 \\
\hline
\end{tabular}

Table 3. Descriptive Statistics of Key Variables

\subsection{Model and Estimation Method}

Since the dependent variable of H1-H3 is binary, the proper model should be probit or logit models. We estimate logit model incorporating two-way fixed effects, as reflected in Equation (1). However, the interaction variables are hard to interpret in a nonlinear model such as the logit model (Hoetker 2007). Besides, the coefficient of the interaction term may not be a reliable estimator of the true estimation. Therefore, we next rerun a set of linear probability model (LPM), which typically results in qualitative similar results as in limited dependent variables models. Firm-level fixed effects and time fixed effects are implemented as dummies and within transformations. In this equation, $i$ indexes thread. $X$ reflects thread level variables such as social media status of customer, politeness of customer's first tweet, and the interaction between social status and politeness. $\beta$ represents the coefficients of interest. The advantage of this two-way fixed effects model is that it addresses both unobserved firm level heterogeneity, as well as any unobserved time trends, both important factors. This approach also controls for the unobserved features of the firm that can reasonably be viewed as time invariant, such as their network position, social capital, and so forth. To avoid the selection bias in testing H4, we apply Heckman correction in these analyses. The basic specification for $\mathrm{H} 4 \mathrm{a}$ is in Equation 2 and the specification for $\mathrm{H} 4 \mathrm{~b}$ is similar. The main independent variables retain the same as those in the model for responses. Additionally, $\lambda$ denotes the inverse Mill's ratio, which is calculated from first stage regression results, and is utilized to control for selection bias. The selection stage of Heckman model is a probit model for whether tweet $i$ is responded by the firm's representative. Except the same variables in Equation 1, we include the usage of url in the tweets, the length of the customer's tweets, and the number of mentions and hashtag in customer's tweet into the selection equation, to satisfy the exclusion restriction condition.

$$
\begin{gathered}
\text { Response }_{i}=X_{i} \beta+\alpha_{i}+\gamma_{t}+\epsilon_{i t} \\
D M_{i} \mid\left(\text { response }_{i}=1\right)=X_{i}^{\prime} \beta^{\prime}+\gamma_{t}+\rho \lambda+\epsilon_{i t}
\end{gathered}
$$

\subsection{Results}

We begin by reporting the main effects of politeness in Table 5. Based on the results, we observe that an increase in the level of politeness has a significant and positive effect on the tendency of getting response by the firm. Specifically, on average, a $10 \%$ increase of politeness increases the likelihood of getting a response from the firm by $3.82 \%$. In addition, the social status of the customer in terms of the number of followers and followings both have a significant and positive effect, which confirm previous finding that firms do take consumer popularity on social media into account in determining whether to respond or not (Gunarathne et al. 2015, 2017). In sum, the results of the main effects model provide clearly strong support for $\mathrm{H} 1-\mathrm{H} 2$.

The baseline main effects provide an indication that politeness has the expected average effects on firm response. Below, we report the estimation results for the interaction effects we proposed in H3H4. In the estimation models, we add our interaction terms, and report the results of this estimation for both logistic and LPM models in Table 5. These re- 
sults indicate support for our hypotheses relating to the firm's strategy used for engaging customers with different politeness level. Specifically, we observe a positive interaction between our indicator of high social status and politeness in the responses model. Based on estimates from Table 5, a $10 \%$ increase in the politeness level of a customer's complaining tweet increases the likelihood of receiving a response from the firm by $2.3 \%$.

\begin{tabular}{|c|c|c|c|c|c|c|}
\hline Model & \multicolumn{3}{|c|}{ Logit } & \multicolumn{3}{|c|}{ LPM } \\
\hline Specification & Spec 1. & Spec 2. & Spec 3. & Spec 1. & Spec 2. & Spec 3. \\
\hline $\log$ (following) & & $\begin{array}{c}0.480^{* * * *} \\
(0.065)\end{array}$ & $\begin{array}{c}0.571 * * * \\
(0.016)\end{array}$ & & $\begin{array}{c}0.446^{* * * *} \\
(0.012)\end{array}$ & $\begin{array}{c}0.475^{\text {**** }} \\
(0.013)\end{array}$ \\
\hline $\log ($ follower) & & $\begin{array}{c}0.221 * * * \\
(0.015)\end{array}$ & $\begin{array}{c}0.643^{* * * *} \\
(0.016)\end{array}$ & & $\begin{array}{c}0.213 * * * * \\
(0.044)\end{array}$ & $\begin{array}{c}0.553^{* * * *} \\
(0.016)\end{array}$ \\
\hline Politeness & $\begin{array}{c}0.375 * * * \\
(0.014)\end{array}$ & $\begin{array}{c}0.391 * * * \\
(0.013)\end{array}$ & $\begin{array}{c}0.212^{* * * *} \\
(0.003)\end{array}$ & $\begin{array}{c}0.295^{* * * *} \\
(0.002)\end{array}$ & $\begin{array}{c}0.353^{* * * *} \\
(0.004)\end{array}$ & $\begin{array}{c}0.305^{* * * *} \\
(0.002)\end{array}$ \\
\hline $\begin{array}{c}\log (\text { follower)* } \\
\text { Politeness }\end{array}$ & & & $\begin{array}{c}0.256^{* * * *} \\
(0.001)\end{array}$ & & & $\begin{array}{c}0.351^{\text {**** }} \\
(0.001)\end{array}$ \\
\hline \#Tweets & $\begin{array}{c}-0.208 * * * \\
(0.013)\end{array}$ & $\begin{array}{c}- \\
0.118^{* * * *} \\
(0.015)\end{array}$ & $\begin{array}{c}0.217^{* * *} \\
(0.015)\end{array}$ & $\begin{array}{c}0.317 * * * \\
(0.015)\end{array}$ & $\begin{array}{c}0.304 * * * \\
(0.011)\end{array}$ & $\begin{array}{c}- \\
0.258^{* * *} \\
(0.015)\end{array}$ \\
\hline \#Likes & $\begin{array}{c}0.107 * * * \\
(0.013)\end{array}$ & $\begin{array}{c}0.117 * * * \\
(0.015)\end{array}$ & $\begin{array}{c}0.217 * * * \\
(0.015)\end{array}$ & $\begin{array}{c}0.371 \text { **** } \\
(0.015)\end{array}$ & $\begin{array}{c}0.267 * * * * \\
(0.008)\end{array}$ & $\begin{array}{c}0.299^{* *} \\
(0.015)\end{array}$ \\
\hline isVerified & $\begin{array}{l}0.108^{* * *} \\
(0.011)\end{array}$ & $\begin{array}{l}0.101^{* * *} \\
(0.015)\end{array}$ & $\begin{array}{l}0.148^{* * *} \\
(0.015)\end{array}$ & $\begin{array}{l}0.571 * * \\
(0.015)\end{array}$ & $\begin{array}{l}0.408^{* *} \\
(0.005)\end{array}$ & $\begin{array}{c}0.418^{* * *} \\
(0.016)\end{array}$ \\
\hline AvgTweetLength & $\begin{array}{c}0.500^{* * * *} \\
(0.015)\end{array}$ & $\begin{array}{c}0.447 * * * \\
(0.015)\end{array}$ & $\begin{array}{c}0.566^{* * * *} \\
(0.015)\end{array}$ & $\begin{array}{c}0.257 * * * * \\
(0.015)\end{array}$ & $\begin{array}{c}0.212 * * * \\
(0.019)\end{array}$ & $\begin{array}{c}0.212^{*} * * * \\
(0.010)\end{array}$ \\
\hline \#hashtags & $\begin{array}{c}0.214 * * * \\
(0.015)\end{array}$ & $\begin{array}{c}0.207 * * * * \\
(0.015)\end{array}$ & $\begin{array}{c}- \\
0.298^{* * *} \\
(0.015)\end{array}$ & $\begin{array}{c}0.255^{* * * *} \\
(0.019)\end{array}$ & $\begin{array}{c}0.117 * * * * \\
(0.015)\end{array}$ & $\begin{array}{c}0.117 * * * * \\
(0.010)\end{array}$ \\
\hline \#mentions & $\begin{array}{c}-0.223 * * * * \\
(0.005)\end{array}$ & $\begin{array}{c}- \\
0.252^{* * *} * \\
(0.015)\end{array}$ & $\begin{array}{c}- \\
0.210^{* * *} \\
(0.015)\end{array}$ & $\begin{array}{c}0.355^{* * *} \\
(0.010)\end{array}$ & $\begin{array}{c}-0.447^{* * *} \\
(0.014)\end{array}$ & $\begin{array}{l}-0.465^{*} \\
(0.010)\end{array}$ \\
\hline Evidentiality & $\begin{array}{c}0.222 * * * \\
(0.011)\end{array}$ & $\begin{array}{c}0.215^{* * * *} \\
(0.015)\end{array}$ & $\begin{array}{c}0.211 * * * \\
(0.015)\end{array}$ & $\begin{array}{c}0.610 * * * * \\
(0.010)\end{array}$ & $\begin{array}{c}0.617 * * * * \\
(0.013)\end{array}$ & $\begin{array}{c}0.521 * * * * \\
(0.010)\end{array}$ \\
\hline Constant & $\begin{array}{c}1.049 * * * \\
(0.002)\end{array}$ & $\begin{array}{c}1.909^{* * * *} \\
(0.005)\end{array}$ & $\begin{array}{c}1.909 * * * \\
(0.005)\end{array}$ & $\begin{array}{c}1.549^{* * * *} \\
(0.003)\end{array}$ & $\begin{array}{c}1.941^{* * * *} \\
(0.004)\end{array}$ & $\begin{array}{r}2.541^{* * * *} \\
(0.005)\end{array}$ \\
\hline Observations & 488,926 & 488,926 & 488,926 & 488,926 & 488,926 & 488,926 \\
\hline $\begin{array}{l}\text { Within R- } \\
\text { squared }\end{array}$ & 0.2425 & 0.2405 & 0.2472 & 0.2228 & 0.2404 & 0.2484 \\
\hline $\begin{array}{c}\text { Firm Fixed } \\
\text { Effect }\end{array}$ & Yes & Yes & Yes & Yes & Yes & Yes \\
\hline $\begin{array}{c}\text { Time Fixed } \\
\text { Effect }\end{array}$ & Yes & Yes & Yes & Yes & Yes & Yes \\
\hline
\end{tabular}

Table 5. Estimation of Main Effect: Dependent variable is a binary indicator, $1=$ firm responded within 7 days of a customer complaint, otherwise 0 . Logistic regression model and Linear probability model with two-way fixed-effects.

\begin{tabular}{|c|c|c|c|c|}
\hline \multirow[b]{2}{*}{ Stage } & \multicolumn{2}{|c|}{$\begin{array}{c}\text { DV=DM, } \\
\text { with Heckman Correction }\end{array}$} & \multicolumn{2}{|c|}{$\begin{array}{l}\text { DV=SentimentChange, } \\
\text { with Heckman Correction }\end{array}$} \\
\hline & First & Second & First & Second \\
\hline $\log$ (following) & $\begin{array}{l}0.106^{* *} \\
(0.008)\end{array}$ & $\begin{array}{c}-0.406^{* * * *} \\
(0.008)\end{array}$ & $\begin{array}{c}-0.209 * * \\
(0.009)\end{array}$ & $\begin{array}{c}0.219 \\
(0.059)\end{array}$ \\
\hline $\log$ (follower) & $\begin{array}{l}0.113 * * \\
(0.008)\end{array}$ & $\begin{array}{c}-0.813^{* * * *} \\
(0.002)\end{array}$ & $\begin{array}{c}0.452 \\
(0.112)\end{array}$ & $\begin{array}{l}-0.182 \\
(0.062)\end{array}$ \\
\hline Politeness & $\begin{array}{c}0.246 \\
(0.138)\end{array}$ & $\begin{array}{c}0.246 \\
(0.138)\end{array}$ & $\begin{array}{l}0.529 * * \\
(0.058)\end{array}$ & $\begin{array}{l}0.629 * * * \\
(0.008)\end{array}$ \\
\hline $\log ($ follower)*Politeness & $\begin{array}{l}-0.107 * \\
(0.013)\end{array}$ & $\begin{array}{c}-0.197 * * \\
(0.003)\end{array}$ & $\begin{array}{c}0.124 \\
(0.110)\end{array}$ & $\begin{array}{c}0.209 \\
(0.107)\end{array}$ \\
\hline \#Tweets & $\begin{array}{c}-0.270 * * \\
(0.015)\end{array}$ & $\begin{array}{c}0.347 * * * \\
(0.015)\end{array}$ & $\begin{array}{c}-0.247 * * \\
(0.075)\end{array}$ & $\begin{array}{l}-0.507^{*} \\
(0.015)\end{array}$ \\
\hline \#Likes & $\begin{array}{c}0.27 \\
(0.15)\end{array}$ & $\begin{array}{r}-0.107^{*} \\
(0.015)\end{array}$ & $\begin{array}{l}-0.347 * * * \\
(0.005)\end{array}$ & $\begin{array}{c}0.447 * * \\
(0.035)\end{array}$ \\
\hline isVerified & $\begin{array}{l}-0.238 \\
(0.105)\end{array}$ & $\begin{array}{l}-0.118 \\
(0.075)\end{array}$ & $\begin{array}{c}0.118^{* * *} \\
(0.05)\end{array}$ & $\begin{array}{l}-0.218^{* *} \\
(0.075)\end{array}$ \\
\hline AvgTweetLength & $\begin{array}{c}0.279 * * * \\
(0.015)\end{array}$ & & $\begin{array}{c}-0.519 * * \\
(0.015)\end{array}$ & \\
\hline \#hashtags & $\begin{array}{l}-0.215^{* * * *} \\
(0.015)\end{array}$ & & $\begin{array}{l}-0.121 \\
(0.085)\end{array}$ & \\
\hline \#mentions & $\begin{array}{c}0.317 * * * \\
(0.015)\end{array}$ & & $\begin{array}{c}0.687 \\
(0.115)\end{array}$ & \\
\hline Evidentiality & $\begin{array}{c}-0.427 * * * \\
(0.015)\end{array}$ & & $\begin{array}{c}-0.182 * * \\
(0.055)\end{array}$ & \\
\hline Inverse Mill's ratio & & $\begin{array}{c}-0.058^{* * * *} \\
(0.002) \\
\end{array}$ & & $\begin{array}{c}-0.038 * * * \\
(0.001)\end{array}$ \\
\hline Observations & & 89,321 & & 89,321 \\
\hline Multiple R-squared & & 0.1446 & & 0.028 \\
\hline Firm Fixed Effect & & Yes & & Yes \\
\hline Time Fixed Effect & & Yes & & Yes \\
\hline
\end{tabular}

Table 6. Estimation of Main Effect. Column 1: Dependent variable is a binary indicator, $1=$ firm redirected the conversation to private channel, otherwise 0 . Linear probability model with two-way fixed-effects. Use Probit model for selection phase in Heckman correction. Column 2: Dependent variable is a continuous measure, indicating the sentiment changes between the customer's first and last tweets. OLS with two-way fixedeffects. Use Probit model for selection phase in Heckman correction.

\section{Discussion and Conclusion}

Motivated by the increasingly popular trend of running customer service on social media platforms, we analyzed tweets sent to and by over 220 firms on Twitter to examine whether the way of complaining and the social status of the customer affect the firm's strategy in engaging customers. Our findings show that companies are more likely to respond to more polite customers, effectively discriminating customers based on their politeness on social media. More interestingly, we also found that firms are less likely to engage the impolite customer with high social status publically; instead, firms prefer to resolve the complaints of these customers in a private channel such as through direct messaging. Furthermore, we found more polite customer is more likely to be satisfied with the firm's response, expressing positive sentiment changes subsequent to the firm's response. 
Our research provides important theoretical contributions to the stream of consumer correspondence handling literature. Although several previous studies examined organizational responsiveness to consumer correspondences of complaints and compliments, to the best of our knowledge, all these were conducted within the frame of traditional customer service. Research in social media-based CRM is still in its infancy. Thus, our research reveals a new dimension of CRM research about how user complains about social media and its impact. This research also has important business implications for the companies practicing various strategies of customer service on social media. We argue that firms need to consider cost and utility in customer service, especially social mediabased ones, so customer service agents can strategically deal with customers when a massive amount of tweets are sent to them seeking for their service and help. To this end, our research provides several insights that can be useful for industry practitioners and social media strategists in investigating the optimal mix of strategies towards effective customer correspondence on social media.

\section{References}

[1] Althoff, T., Danescu-Niculescu-Mizil, C., \& Jurafsky, D. (2014). How to ask for a favor: A case study on the success of altruistic requests. arXiv preprint arXiv: 1405.3282 .

[2] Ambady, N., Koo, J., Lee, F., \& Rosenthal, R. (1996). More than words: Linguistic and nonlinguistic politeness in two cultures. Journal of Personality and Social Psychology, 70(5), 996.

[3] Andersson, L. M., \& Pearson, C. M. (1999). Tit for tat? The spiraling effect of incivility in the workplace. Academy of management review, 24(3), 452-471.

[4] Blodgett, J. G., Hill, D. J., \& Tax, S. S. (1997). The effects of distributive, procedural, and interactional justice on postcomplaint behavior. Journal of retailing, 73(2), 185-210.

[5] Bonchi, F., Castillo, C., Gionis, A., \& Jaimes, A. (2011). Social network analysis and mining for business applications. ACM Transactions on Intelligent Systems and Technology (TIST), 2(3), 22.

[6] Brennan, S. E., \& Ohaeri, J. O. (1999, March). Why do electronic conversations seem less polite? The costs and benefits of hedging. In ACM SIGSOFT Software Engineering Notes (Vol. 24, No. 2, pp. 227-235). ACM.
[7] Brown, P., \& Levinson, S. C. (1978). Universals in language usage: Politeness phenomena. In Questions and politeness: Strategies in social interaction (pp. 56311). Cambridge University Press.

[8] Burke, M., \& Kraut, R. (2008, November). Mind your Ps and Qs: the impact of politeness and rudeness in online communities. In Proceedings of the 2008 ACM conference on Computer supported cooperative work (pp. 281-284). ACM.

[9] Cha, M., Haddadi, H., Benevenuto, F., \& Gummadi, P. K. (2010). Measuring user influence in twitter: The million follower fallacy. Icwsm, 10(10-17), 30.

[10] Danescu-Niculescu-Mizil, C., Sudhof, M., Jurafsky, D., Leskovec, J., \& Potts, C. (2013). A computational approach to politeness with application to social factors. arXiv preprint arXiv:1306.6078.

[11] Davidow, M. 2000. "The Bottom Line Impact of Organizational Responses to Customer Complaints," Journal of Hospitality \& Tourism Research (24:4), pp. 473-4.

[12] Del Río-Lanza, A. B., Vázquez-Casielles, R., and Díaz-Martín, A. M. 2009. "Satisfaction with Service Recovery: Perceived Justice and Emotional Responses," Journal of Business Research (62:8), pp. 775-781.

[13] Domingos, P., \& Richardson, M. (2001, August). Mining the network value of customers. In Proceedings of the seventh ACM SIGKDD international conference on Knowledge discovery and data mining (pp. 57-66). ACM.

[14] Duthler, K. W. (2006). The politeness of requests made via email and voicemail: Support for the hyperpersonal model. Journal of Computer-Mediated Communication, 11(2), 500-521.

[15] Goodwin, C., \& Ross, I. (1992). Consumer responses to service failures: influence of procedural and interactional fairness perceptions. Journal of Business research, 25(2), 149-163.

[16] Gunarathne, P., Rui, H., \& Seidmann, A. (2015, January). Customer Service on Social Media: The Effect of Customer Popularity and Sentiment on Airline Response. In System Sciences (HICSS), 2015 48th Hawaii International Conference on (pp. 3288-3297). IEEE.

[17] Gunarathne, P., Rui, H., \& Seidmann, A. (2017, January). What Drives Successful Complaint Resolutions on Social Media?: Evidence from the Airline Industry. In Proceedings of the 50th Hawaii International Conference on System Sciences. 
[18] Heckman, J. J. (1977). Sample selection bias as a specification error (with an application to the estimation of labor supply functions).

[19] Holmes, J., \& Schnurr, S. (2005). Politeness, humor and gender in the workplace: negotiating norms and identifying contestation.

[20] Hoetker, G. (2007). The use of logit and probit models in strategic management research: Critical issues. Strategic Management Journal, 28(4), 331-343.

[21] Hutto, C. J., \& Gilbert, E. (2014, May). Vader: A parsimonious rule-based model for sentiment analysis of social media text. In Eighth international AAAI conference on weblogs and social media.

[22] Hyland, K. (2005). Metadiscourse. John Wiley \& Sons, Inc.

[23] Kaplan, D. (1999). What is meaning? Explorations in the theory of meaning as use. Brief version-draft 1 . Manuscript, UCLA.

[24] Kong, L., Schneider, N., Swayamdipta, S., Bhatia, A., Dyer, C., \& Smith, N. A. (2014). A dependency parser for tweets. EMNLP

[25] Laplante, D., \& Ambady, N. (2003). On how things are said: Voice tone, voice intensity, verbal content, and perceptions of politeness. Journal of Language and Social Psychology, 22(4), 434-441.

[26] Laschinger, H. K. S., \& Finegan, J. E. (2004, August). EMPOWERMENT, INTERACTIONAL JUSTICE, TRUST AND RESPECT: A NURSING RECRUITMENT AND RETENTION STRATEGY. In Academy of management proceedings (Vol. 2004, No. 1, pp. C1-C6). Academy of Management.

[27] Ma, L., Sun, B., \& Kekre, S. (2015). The Squeaky Wheel Gets the Grease-An empirical analysis of customer voice and firm intervention on Twitter. Marketing Science, 34(5), 627-645.

[28] Maxham III, J. G., \& Netemeyer, R. G. (2002). A longitudinal study of complaining customers' evaluations of multiple service failures and recovery efforts. Journal of marketing, 66(4), 57-71. Chicago

[29] McColl-Kennedy, J. R., \& Sparks, B. A. (2003). Application of fairness theory to service failures and service recovery. Journal of service research, 5(3), 251266.

[30] Mitra, T., \& Gilbert, E. (2014, February). The language that gets people to give: Phrases that predict success on kickstarter. In Proceedings of the 17th ACM conference on Computer supported cooperative work \& social computing (pp. 49-61). ACM.
[31] Mollick, E. (2014). The dynamics of crowdfunding: An exploratory study. Journal of business venturing, 29(1), 1-16.

[32] Nikbin, D., Armesh, H., Heydari, A., and Jalalkamali, M. 2011. "The Effects of Perceived Justice in Service Recovery on Firm Reputation and Repurchase Intention in Airline Industry," African Journal of Business Management (5:23), pp. 9814-9822.

[33] Obeng, S. G. (1997). Language and politics: Indirectness in political discourse. Discourse \& Society, 8(1), 49-83. Chicago

[34] Richins, M. L. 1983. "Negative Word-of-mouth by Dissatisfied Consumers: A Pilot Study," Journal of Marketing (47:1), pp. 68-78.

[35] Rogers, P. S., \& Lee-Wong, S. M. (2003). Reconceptualizing politeness to accommodate dynamic tensions in subordinate-to-superior reporting. Journal of Business and Technical Communication, 17(4), 379-412.

[36] Sen, A., and Sinha, A. P. 2011. "IT Alignment Strategies for Customer Relationship Management," Decision Support Systems (51:3), pp. 609-619.

[37] Smith, A. K., Bolton, R. N., and Wagner, J. 1999. "A Model of Customer Satisfaction With Service Encounters Involving Failure and Recovery," Journal of Marketing Research (36:3), pp. 356-372.

[38] Sreenivasan, N. D., Lee, C. S., and Goh, D. H. L. 2012. "Tweeting the Friendly Skies: Investigating Information Exchange Among Twitter Users About Airlines," Program: Electronic Library and Information Systems (46:1), pp. 21-42.

[39] Strauss, J., \& Hill, D. J. (2001). Consumer complaints by e-mail: an exploratory investigation of corporate responses and customer reactions. Journal of Interactive Marketing, 15(1), 63-73.

[40] Tax, S. S., Brown, S. W., and Chandrashekaran, M. 1998. "Customer Evaluations of Service Complaint

[41] Watts, D. J., \& Dodds, P. S. (2007). Influentials, networks, and public opinion formation. Journal of consumer research, 34(4), 441-458. 